\title{
High Speed OTDM-DWDM Bit Compressed Network for Long-Haul Communication
}

\author{
Tadbirul Islam and Mohammad Nasir Uddin
}

\begin{abstract}
This paper represents an optical communication network design that incorporates both OTDM and DWDM techniques which provides up to $240 \mathrm{Gbit} / \mathrm{s}$ data transfer rate, long-haul communication distance of $2700 \mathrm{~km}$ with a maximum number of 384 channels in this designed architecture. Each channel has a bitrate of $625 \mathrm{Mbit} / \mathrm{s}$ that follows optical signal hierarchy OC-12, STS-12 (SONET ANSI), and STM-4 (SDH CCITT), and the design maintains standard parameters for commercially available channel grids at $100 \mathrm{GHz}$ spacing. The communication is done by Single Mode Fiber (SMF) of $50 \mathrm{~km}$ and Dispersion Compensating Fiber (DCF) of $10 \mathrm{~km}$ followed by one optical amplifier gain in each span. Bit error rate (BER) remains significantly low while transmission distance for only OTDM is $18000 \mathrm{~km}$ at a BER $<10^{-12}$, and for the hybrid OTDM-DWDM it is $2700 \mathrm{~km}$ at a BER $<1^{-16}$. Both values are measured under 128 bits sequence length. Three compression stages are used for 8 channels each in order to minimize the gap between bits, and to utilize the space for more channels within a specific time window.
\end{abstract}

Keywords-DWDM; high-speed networks; optical time division multiplexing; OTDM-DWDM; packet-interleaved bit compression

\section{INTRODUCTION}

Fiber optic technology has grown tremendously over the years all around the world. Fiber also shows up in research institutions, colleges and universities, as well as in the aerospace, biomedical, and chemical industries. In this modern generation, the main crisis that fiber optic communication system is facing is the need of higher data rates, higher bandwidth and high speed data transfer. The need of transferring large amount of data, gigabyte sized files, and recently invented $4 \mathrm{k} 60 \mathrm{~Hz}$ high resolution videos require higher bitrates to minimize the time duration of file transfer worldwide.

The existing technologies for the ever-growing fiber optics

\section{Tadbirul Islam}

American International University - Bangladesh

Dhaka, Bangladesh

ti89691@gmail.com

\section{Mohammad Nasir Uddin}

American International University - Bangladesh

Dhaka, Bangladesh

drnasir@aiub.edu communication uses a combination of multiplexing techniques with Wavelength Division Multiplexing (WDM) and some backbone techniques such as Orthogonal Frequency Division Multiplexing (OFDM) [1], Optical Time Division Multiplexing (OTDM) [2], Optical Code Division Multiplexing (OCDM) [3], Space Division Multiplexing (SDM) [4], and Orbital Angular Momentum (OAM) [5] etc. However, there are more existing technologies, and are still under development. The major problem is the need of higher bandwidth and obtaining the desired data rate to as maximum as possible. This paper represents a new proposed technique that incorporates OTDM and DWDM together [2], [6], [7]. Both of these multiplexing techniques have very high bitrate capabilities, can control and occupy a lot of channels individually under the transmission window of $1.55 \mu \mathrm{m}$. Transmission distance for fiber optic communication system is another major fact in the existing WDM technique [8]. WDM system has covered a distance of $500 \mathrm{~km}$ [9], $515 \mathrm{~km}$ [10], $632 \mathrm{~km}$ [11], and $700 \mathrm{~km}$ [12] in several proposed techniques by other researchers. On the other hand, OTDM is a powerful and scalable technique to investigate high-speed data transmission systems, related signal processing and monitoring technologies at serial data rates beyond the bandwidth limitation of optoelectronics [13], [14].

The proposed technique in this paper has achieved bitrate of $240 \mathrm{Gbit} / \mathrm{s}$ with the combination of OTDM-DWDM technique within $1.55 \mu \mathrm{m}$ transmission window for $2700 \mathrm{~km}$ long-haul communication. A total of 48 channels are transmitted using OTDM for each WDM input, then 8 channels of WDM are multiplexed at the transmission end for making a total of 384 channels. At the receiver end, all 8 channels of WDM are demultiplexed along with 48 channels of OTDM from each output terminal, making sure that all 384 user channels are demodulated successfully. The bitrate is set to 625 $\mathrm{Mbit} / \mathrm{s}$ for each channel that provides up to $240 \mathrm{Gbit} / \mathrm{s}$ in total communication.

\section{PRINCIPLE OPERATION}

The entire system starts with modulation of OTDM and multiplex in WDM at the transmission side, and then demultiplex of WDM and demodulation of OTDM at the receiver side, respectively. The very first part is modulating 8 individual channels with three compression stages in OTDM. Afterwards, same set of channels are created to make 48 channels in total and multiplexed with calculated time delay in 
order to best fit all other channels in between the empty time slots created by compression stages. In this network architecture, adapting to compression stage helps to accommodate more and more channels because it provides free time slots by compressing bit interval [15], [16]. Thus, a complete transmission side is designed that goes into a specific wavelength $(1550.12 \mathrm{~nm})$ of the WDM system. In the same way other 48 channels from OTDM are connected as input for another wavelengths $(1550.92 \mathrm{~nm})$. In WDM, 8 channels are taken as input for making a total of 384 channels from OTDM into WDM multiplexer side.

At the beginning of the receiver, there is a WDM demultiplexer with 8 channels of output that goes into demodulating the rest 48 OTDM channels in each WDM channel with synchronized time delay [13], [17]. Therefore, all 384 channels goes to respective recipients. In between the transmitter and receiver, there are segments each having a Single Mode Fiber (SMF) of $50 \mathrm{~km}$ followed by a Dispersion Compensating Fiber (DCF) of $10 \mathrm{~km}$. An optical amplifier is used for optical power gain after every $60 \mathrm{~km}$ of the span.

\section{A. Abbreviations and Acronyms}

WDM $=$ Wavelength division multiplexing

DWDM $=$ Dense wavelength division multiplexing

OTDM $=$ Optical time division multiplexing

OFDM $=$ Orthogonal frequency division multiplexing

OCDM $=$ Optical code division multiplexing

$\mathrm{SDM}=$ Space division multiplexing

OAM $=$ Orbital angular momentum

PRBS $=$ Pseudo Random Bit Sequence

FEC $=$ Forward Error Correction

$\mathrm{Ych} \times \mathrm{Z}=\mathrm{Y}$ number of input channel(s) and $\mathrm{Z}$ number of output(s)

$\mathrm{Z} \times \mathrm{Ych}=\mathrm{Z}$ number of input(s) and $\mathrm{Y}$ number of output channel(s)

\section{NETWORK SETUP}

The design of OTDM-DWDM network consists of two techniques, one is the OTDM, and the other is DWDM. OTDM modulation and demodulation, along with DWDM mux and demux are simulated separately for best optimization. In the process, both techniques are adjusted for better OSNR, merged together at the final stage, and further tuned for efficient output.

\section{A. OTDM Signal}

The OTDM modulation consists of 48 channels, in six sets of 8 channels. Each channel are muxed at $625 \mathrm{Mbit} / \mathrm{s}$ bitrate, and passed through compression stage followed by calculated time delay. Channel bit rate follows OC-12 standards [18]. While adding channels into each power combiner component, maximum $2 \mathrm{~dB}$ loss has been counted as design margin just because in real time scenario any of the components may show power surge due to temperature, rough or ambient weather condition etc. But in demodulation side, maximum $1 \mathrm{~dB}$ loss has been counted for each power splitter component. Laser power of every channel is set to $5 \mathrm{dBm}$ with linewidth of $10 \mathrm{kHz}$

A channel is designed using one $\mathrm{CW}$ laser diode, a Pseudo Random Bit Sequence generator with a bit rate of $625 \mathrm{Mbit} / \mathrm{s}$, a Return-to-Zero pulse generator, then all three components are connected to an amplitude modulator followed by an optical time delay as shown in Fig. 1:-

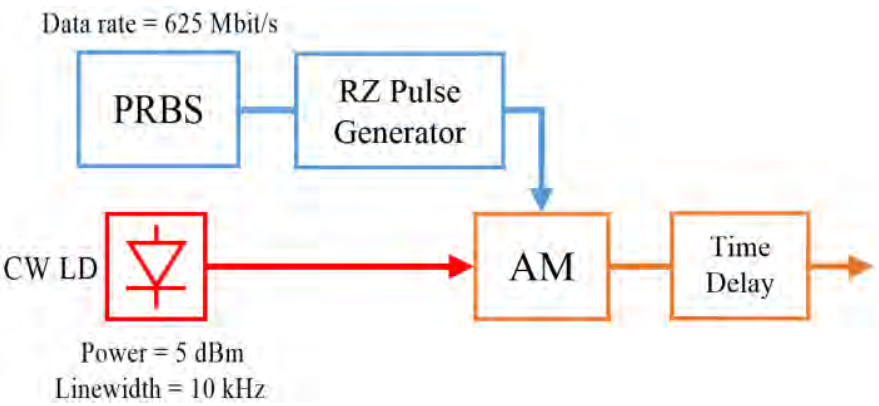

Fig. 1. Design of a single channel. A PRBS generating $625 \mathrm{Mbps}$ data is coupled with $5 \mathrm{dBm} \mathrm{CW}$ Laser using amplitude modulator, whereas time delay fixes redundancies with other channels of similar structure. (Legend: $P R B S=$ Pseudo-Random Bit Sequence, $R Z=$ Return-to-Zero, $C W L D=$ Continuous Wave Laser Diode, $A M=$ Amplitude Modulator)

Finally all sets are combined at the end of transmission side as shown in Fig. 2:-

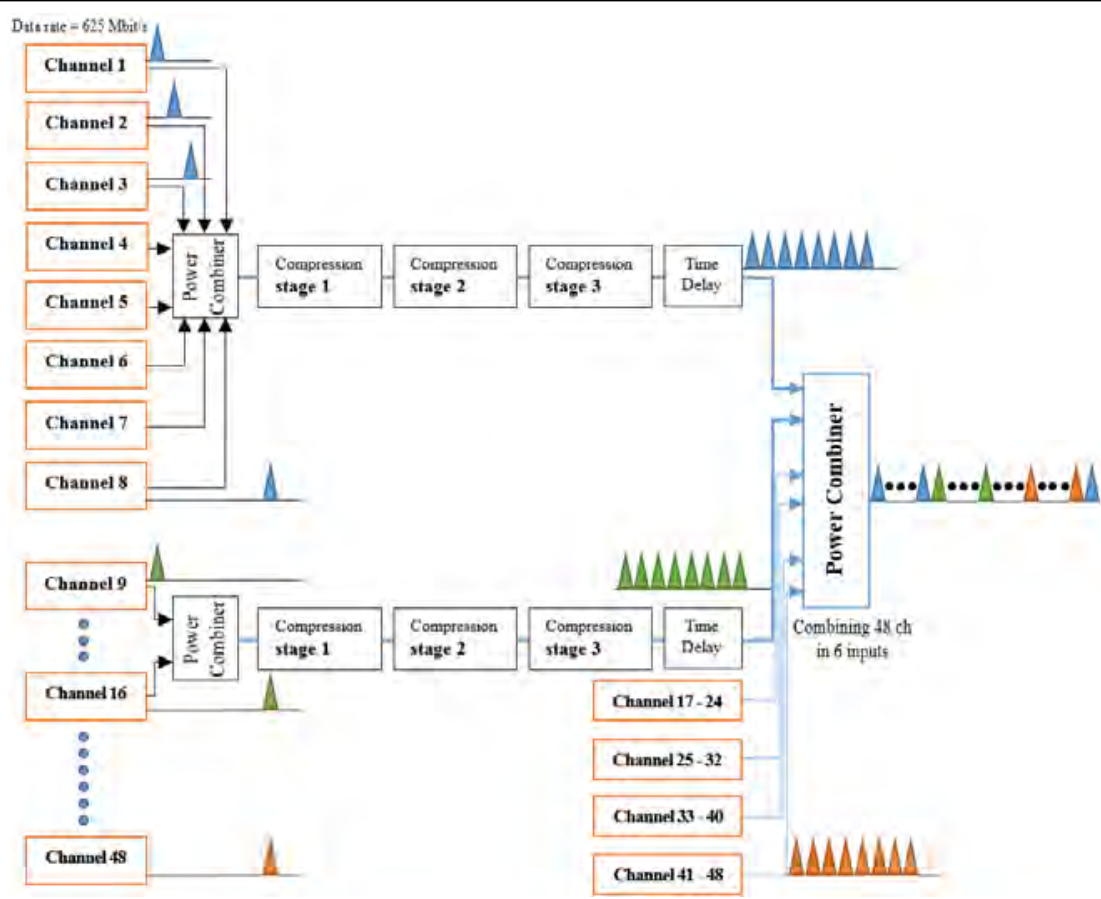

Fig. 2. OTDM transmitter sub-system, six individual $8 \mathrm{ch} \times 1$ power combiner accumulates eight channels each, making a total of 48 user channels into one $6 \mathrm{ch} \times 1$ power combiner. 
At the receiving side, a power splitter takes out 6 outputs to another six splitters where each splitter divides into 8 outputs in order to demodulate each channel from the transmission end. Demodulation starts with a clock generator, a Return-to-Zero pulse generator, an electrical time delay component that goes into one terminal of the amplitude modulator while the other terminal is connected to one of the splitters. Demodulation of each and every channel is successfully achieved at synchronized time delay. The other five splitters also demodulates 8 channels each that makes 48 channel outputs as shown in Fig. 3:- finalize the process of demodulation. In between the WDM MUX and DEMUX there are fiber expanding about $2700 \mathrm{~km}$ in segments of $60 \mathrm{~km}$ that have SMF of $50 \mathrm{~km}$, DCF of $10 \mathrm{~km}$, and one optical amplifier for regaining dissipated power at the end of each segment. The whole setup is shown in Fig. 4.

\section{RESULT AND ANALYSIS}

The design for both OTDM and hybrid OTDM-DWDM are done successfully and mapped accurately. Nevertheless, absolute timing precision is implicated so that there is no loss in message bits.

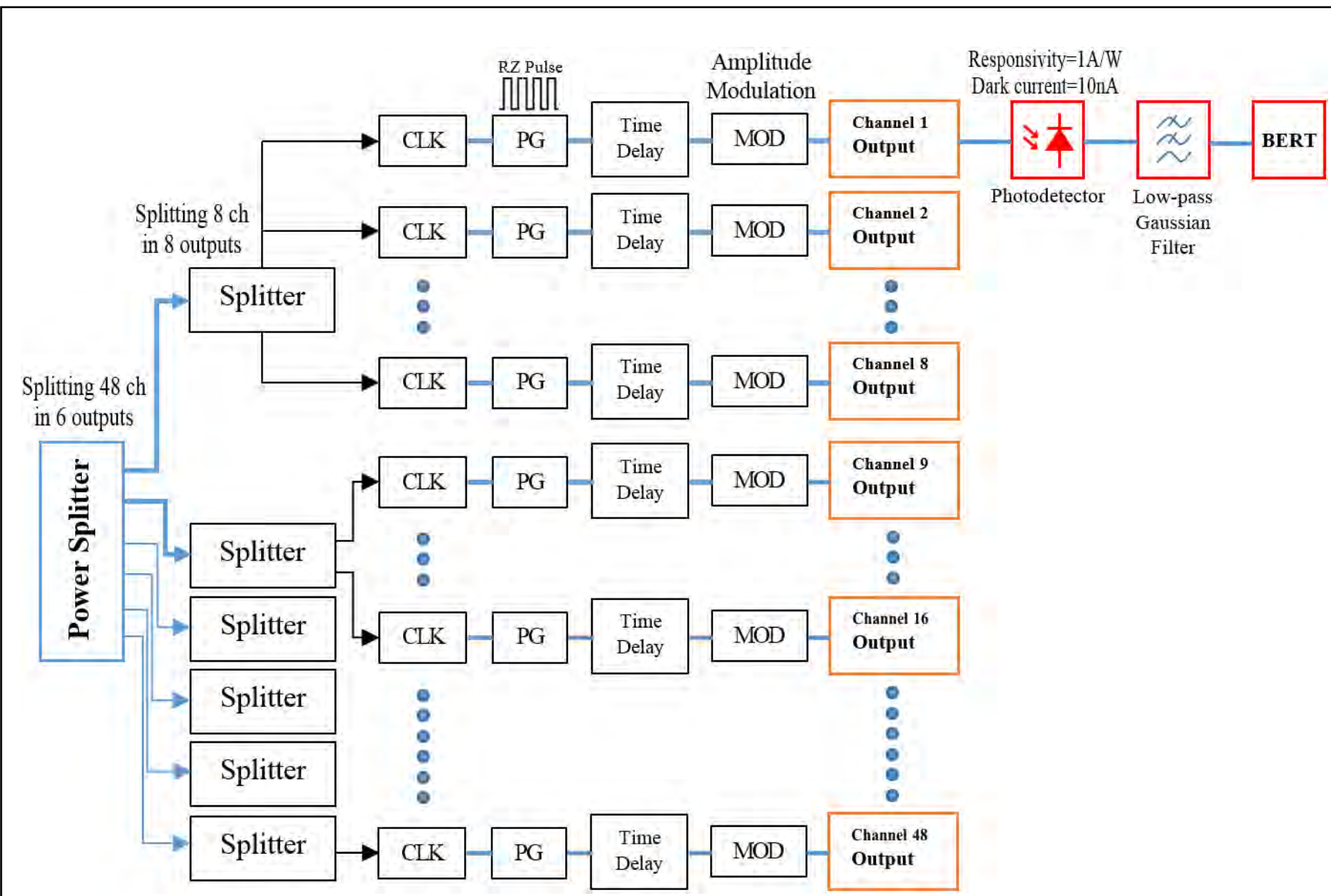

Fig. 3. OTDM receiver sub-system, one $1 \times 6 \mathrm{ch}$ splitter takes out 48 channels into six individual $1 \times 8 \mathrm{ch}$ power splitters, each splitter contains messages from corresponding channel which are retrieved at calculated time delay from each output of the splitter. (Legend: $\mathrm{CLK}=\mathrm{clock}$, PG $=$ pulse generator, $\mathrm{MOD}=$ modulation, $\mathrm{BERT}=$ Bit Error Ratio Tester)

\section{B. DWDM Signal}

For DWDM system, at the transmission end, 8 channel WDM MUX is used to take 384 channels as input. Each input has 48 channels from OTDM. The proposed technique is designed using 1550.12, 1550.92, 1551.72, 1552.52, 1553.33, 1554.13, 1554.94, and $1555.75 \mathrm{~nm}$ following the ITU-T G.694.1 (02/2012) standard 0.8 nm DWDM channel spacing grid [19].

For DEMUX, at the receiving end, each channel from 8 outputs of WDM takes out 48 channels from OTDM in order to

\section{A. OTDM Network}

For designing the OTDM, accurate time calculation allows to best fit the 48 channels into empty time frame. In order to limit SMF non-linear loss, to keep transmission power less than $0 \mathrm{dBm}$, and considering losses within devices, the power of each laser is set to $5 \mathrm{dBm}$ or, $3.1628 \mathrm{~mW}$ only. Single user channel bitrate is $625 \mathrm{Mbit} / \mathrm{s}$. Bit sequence generator has no leading or trailing zeros. For $625 \mathrm{Mbit} / \mathrm{s}$ bitrate and 128 bits sequence length, transmission side data structure has been observed in Fig. 5. 


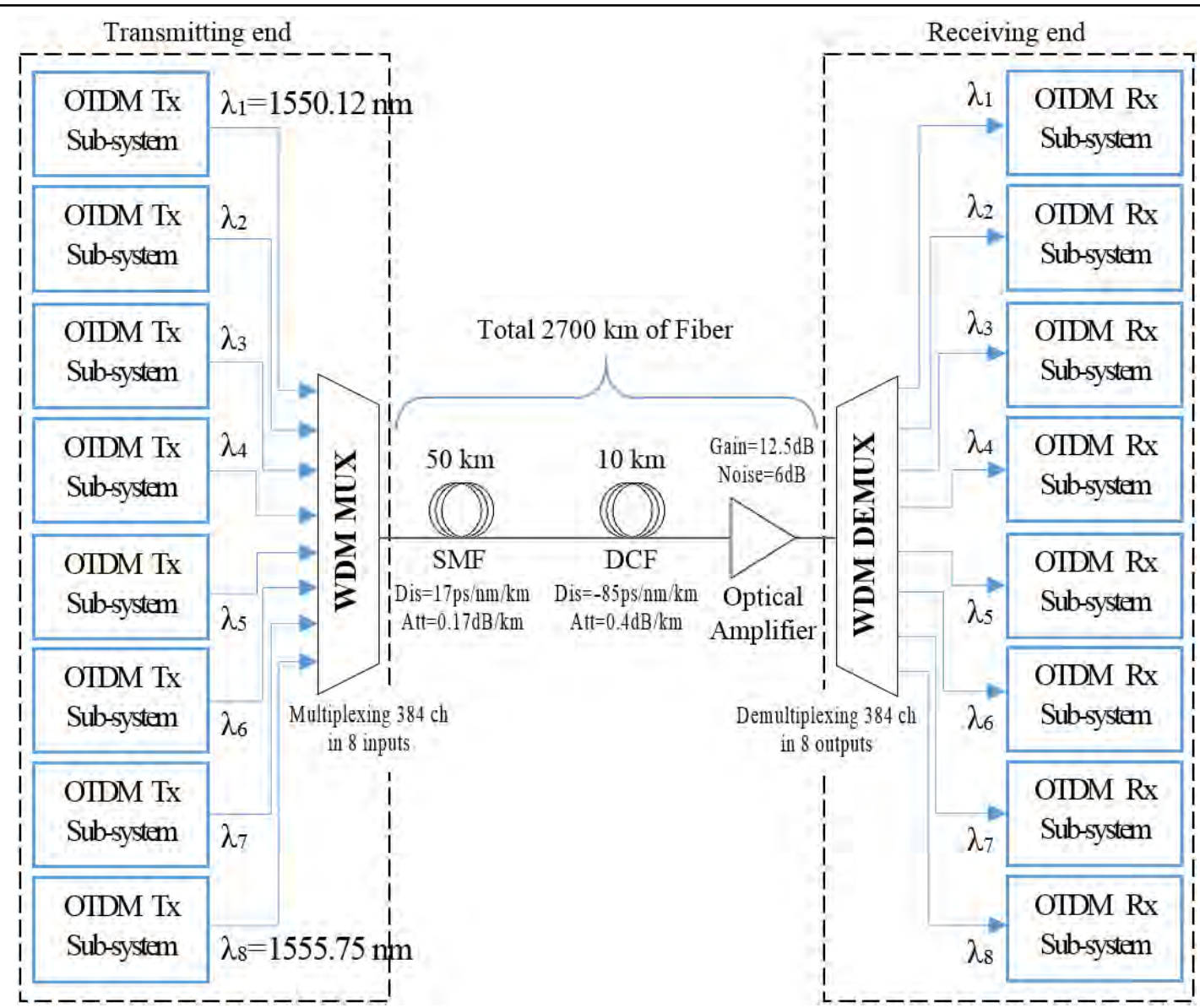

Fig. 4. OTDM-DWDM system, total 384 channels are transferred throughput $240 \mathrm{Gbit} / \mathrm{s}$ data rate that has 2700 kilometers long-haul transmission capability. (Legend: $\mathrm{SMF}=$ Single Mode Fiber, $\mathrm{DCF}=$ Dispersion Compensating Fiber)

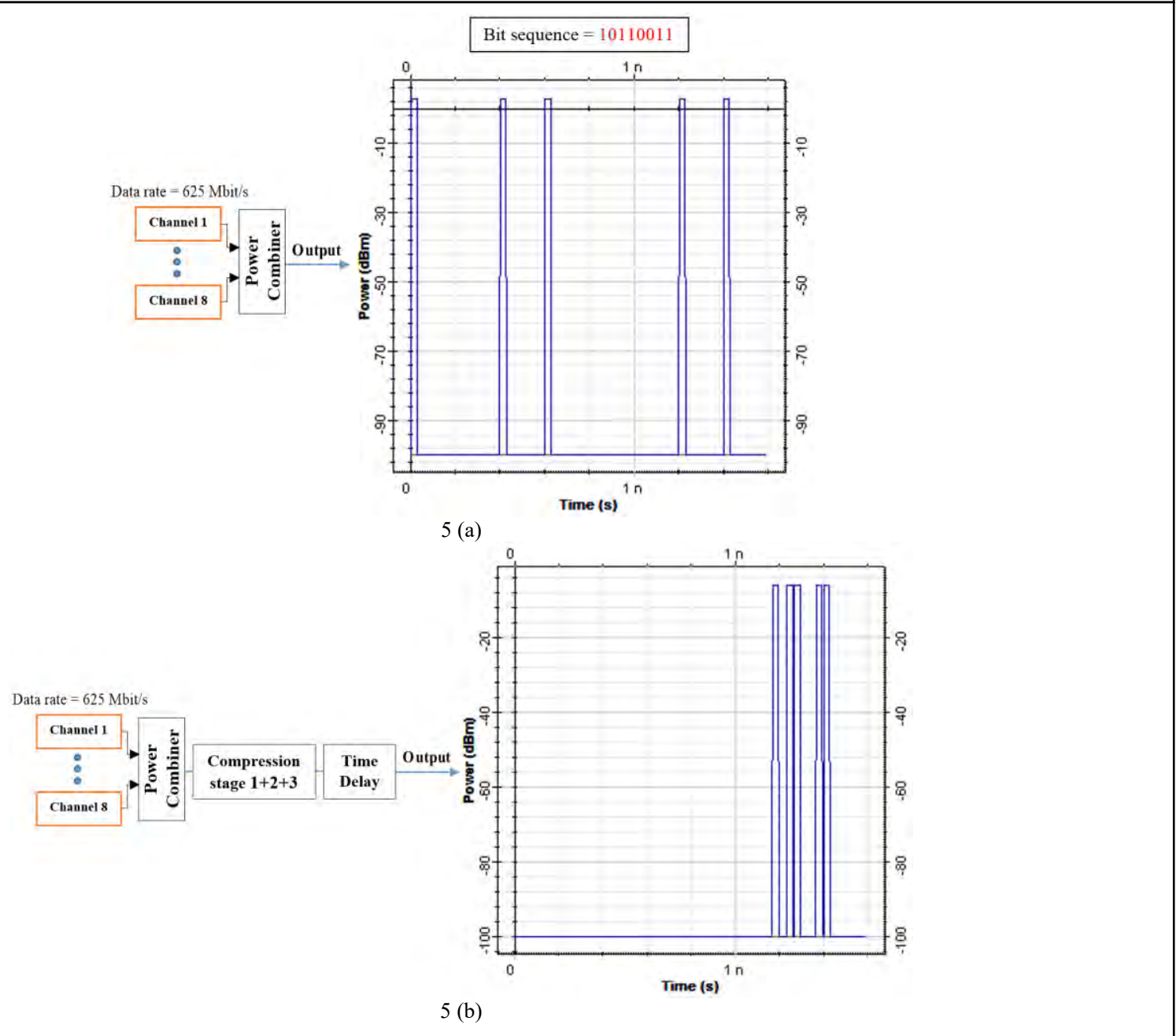




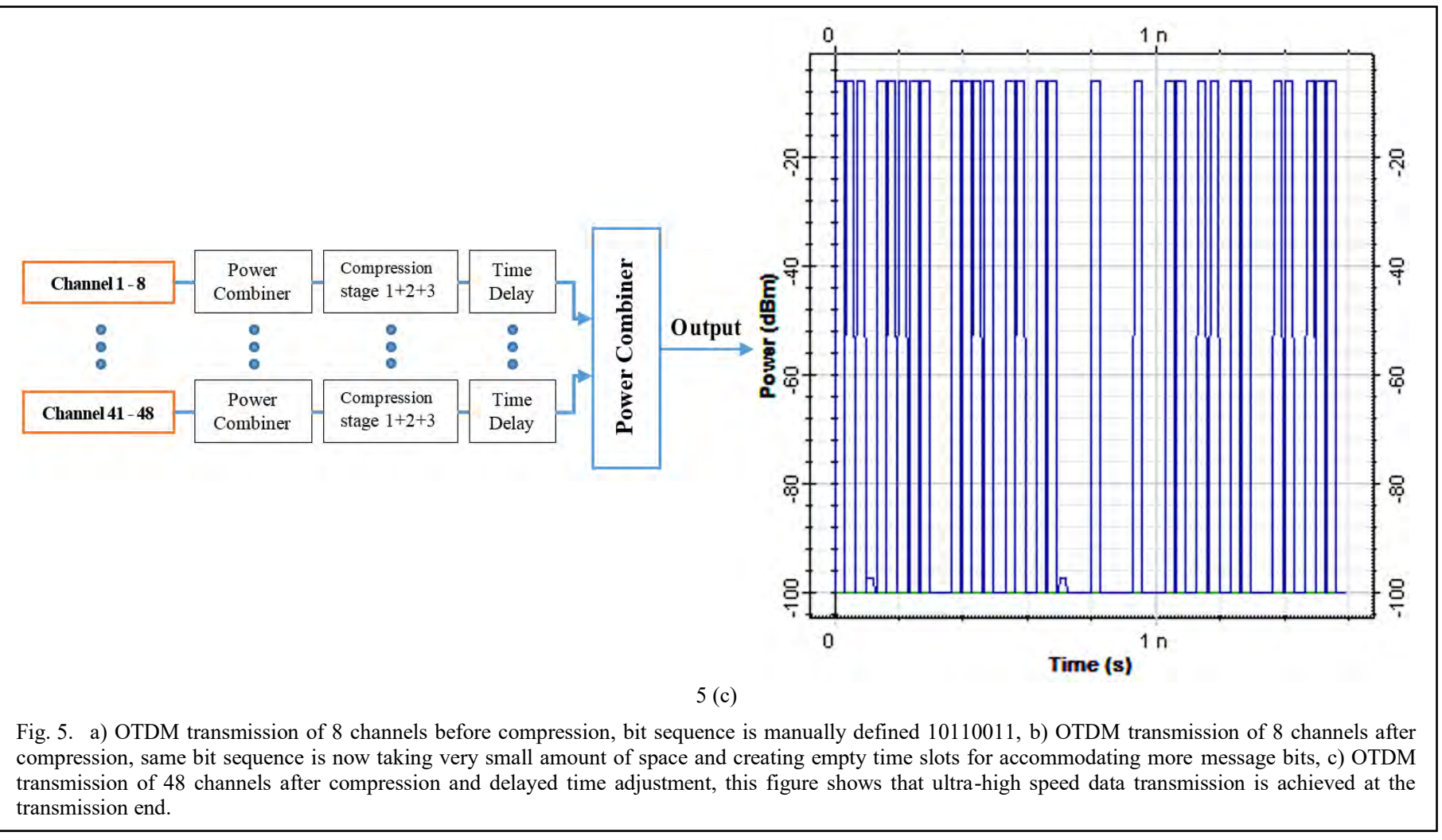

\section{B. BER Result of OTDM}

At $1550.12 \mathrm{~nm}$, the bit error rate (BER) seen through 3R generator at channel 1 stays well under $10^{-12}$ at a transmission distance of $18000 \mathrm{~km}$ in OTDM for 128 bits sequence length. Maximum Q-factor is 6.78312, minimum BER is $1.15617 \times 10^{-12}$, corresponding eye-diagram shown in Fig. 6:-
Fig. 6 shows eye diagram for return-to-zero pulse generator in OTDM signal. RZ signals do not have any crossing points in eye diagram because pulses are returning back to zero $(0)$ after each bit. Jitter is measured at the $50 \%$ level of either falling or rising edge of the eye, this is also known as the RMS jitter.

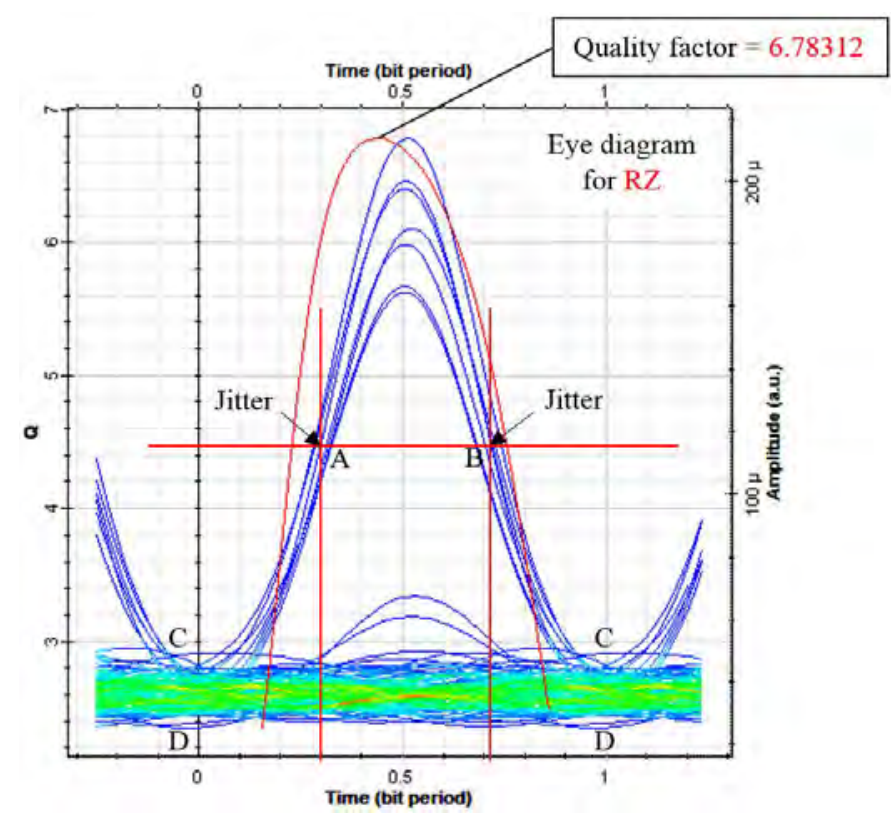

(a)

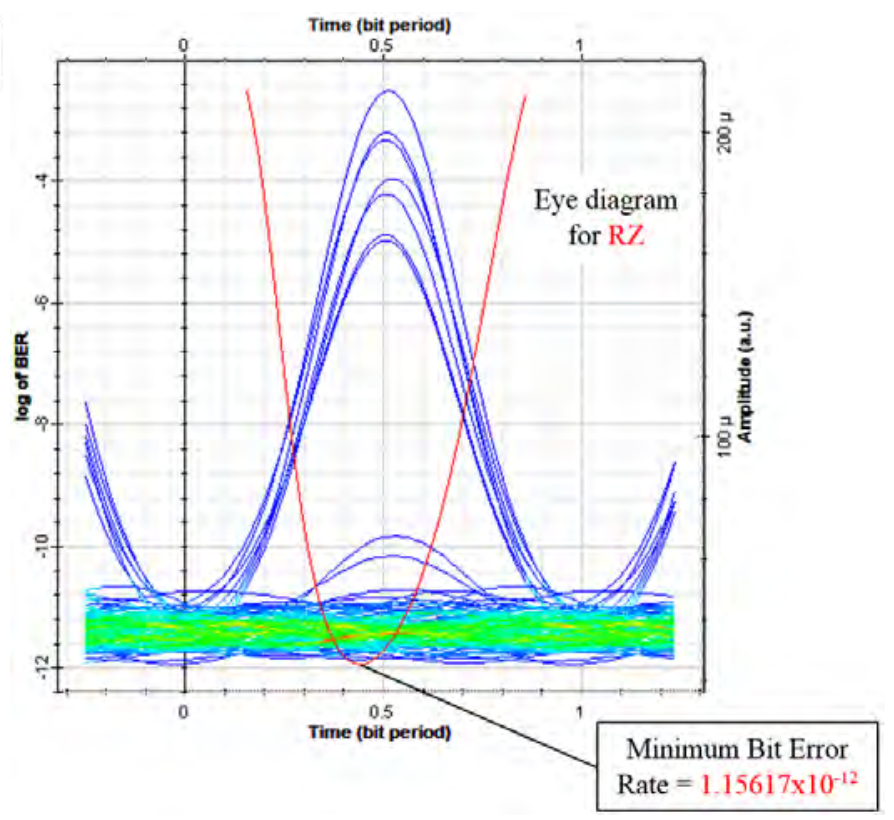

(b)

Fig. 6. a) Q-factor at ch-1 marked by the red curve is 6.78312 , b) Min. BER at ch-1 marked by the red curve is $1.15617 \times 10^{-12}$. 
In order to measure BER and Q-factor at the receiver terminal, PRBS are used as clock generator, and low pass Gaussian filter is connected after Avalanche Photo Diode (APD) that has a cut-off frequency of $(0.75 \times$ Bitrate $)$, depth of $100 \mathrm{~dB}$, and 1 st order filter. APD photo-detector has a responsivity of $1 \mathrm{~A} / \mathrm{W}, 10 \mathrm{nA}$ dark current, thermal noise of $1 \times 10^{-22} \mathrm{~W} / \mathrm{Hz}$. The values are taken without any forward error correction (FEC).

The proposed technique in this paper allows $18000 \mathrm{~km}$ transmission at $1550.12 \mathrm{~nm}$ with BER of $1.15617 \times 10^{-12}$ using 48 channels with PRBS, the odds of signal dispersion, shifting of data bits are also accounted for. Any change in laser power can greatly deteriorate transmission quality, some values taken from the simulation at channel 1 are included in Table 1 , and a graph showing $\log (\mathrm{BER})$ and transmission distance limitation due to different magnitude of laser power are represented in Fig. 7:-

TABLE I. MEASURING BER WITH RESPECT TO TRANSMISSION DISTANCE

\begin{tabular}{|c|c|c|c|c|}
\hline \multirow{2}{*}{$\begin{array}{c}\text { Laser } \\
\text { Power } \\
(\mathbf{d B m})\end{array}$} & $\mathbf{4 9 8 0}$ & $\mathbf{9 9 6 0}$ & $\mathbf{1 5 0 0 0}$ & $\mathbf{1 8 0 0 0}$ \\
\cline { 2 - 5 } & -88.1189 & -30.8756 & -14.7909 & -11.937 \\
\hline $\mathbf{5}$ & -64.8025 & -24.3698 & -13.0285 & -10.5681 \\
\hline $\mathbf{4}$ & -46.8056 & -17.3952 & -10.0836 & -8.04046 \\
\hline $\mathbf{3}$ & \multicolumn{4}{|c|}{$\log (\mathrm{BER})$} \\
\hline
\end{tabular}

\section{Hybrid OTDM-DWDM Network}

For designing the hybrid OTDM-DWDM system, choosing wavelength carefully is a great factor because power attenuation and dispersion of message bits take place under different wavelengths. Network setup in this paper is done within $1.55 \mu \mathrm{m}$ transmission window because it is the lowest attenuation window for SMF, but dispersion matters now. Changing wavelength from $1550 \mathrm{~nm}$ to $1560 \mathrm{~nm}$ will make a significant dispersion that will cause shifting in pulse train and message bit stream, resulting defective demodulation of message, degrading BER value, and limiting transmission distance as well. In order to maintain a better BER and communication distance, wavelength width ranges from $1550 \mathrm{~nm}$ to $1556 \mathrm{~nm}$, which has minimum attenuation loss, improved amount of BER and allows maximum distance. All WDM channels designed in this network transmit the data within 1550.12, 1550.92, 1551.72, 1552.52, 1553.33, $1554.13,1554.94$, and $1555.75 \mathrm{~nm}$ wavelength [19].

Both MUX and DEMUX have 8 channels input and output respectively, with a noise threshold of $-100 \mathrm{~dB}$ and $3 \mathrm{~dB}$ noise dynamicity. MUX is designed with a bandwidth of $0.8 \mathrm{~nm}$, Bessel type filter, filter order is 2. For DEMUX, bandwidth is $0.8 \mathrm{~nm}$, same Bessel type filter with an order of 2, and resampled at $3.2 \times 10^{11} \mathrm{~Hz}$. A Gaussian optical filter is connected at each output terminal with a bandwidth of $90 \mathrm{GHz}$ so that noises can be filtered out within respective wavelengths.

GRAPH I. $\quad \log (\mathrm{BER})$ vs. Transmission Distance

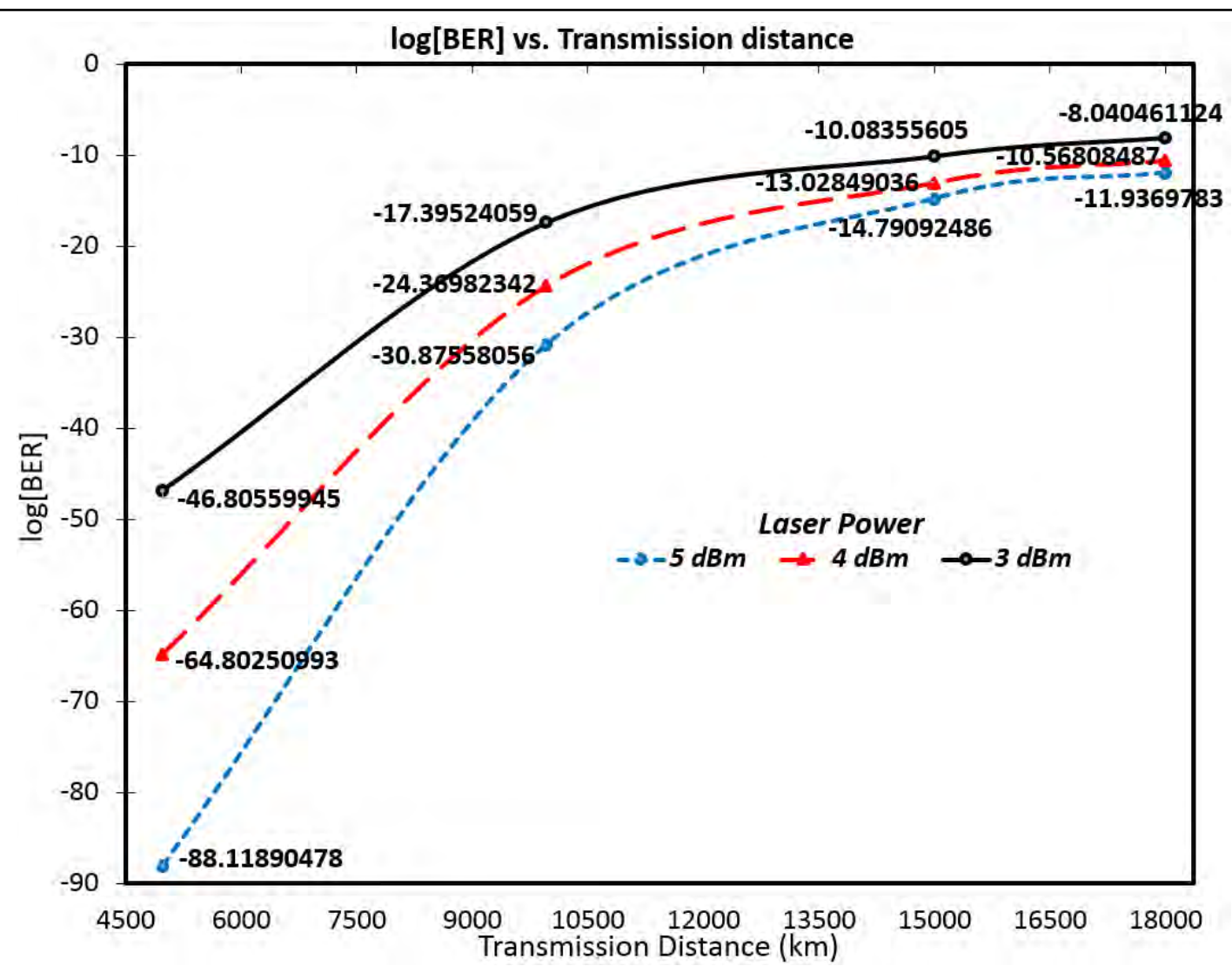

Fig. 7. $\log (\mathrm{BER})$ vs. transmission distance graph from ch-1 shows the effects on transmission due to laser power. Laser power at $5 \mathrm{dBm}$ for all CW lasers contribute to better BER over the distance of transmission than that of 3 and $4 \mathrm{dBm}$. 


\section{BER Result of OTDM-DWDM}

At $1550.12 \mathrm{~nm}$, the bit error rate (BER) seen through 3R generator at channel 1 stays well under $10^{-12}$ at a transmission distance of $2700 \mathrm{~km}$ in OTDM-DWDM combined system for 128 bits sequence length. Maximum Q-factor is 7.88543, minimum BER is $2.68103 \times 10^{-16}$, and corresponding eyediagram is presented in Fig.8:-

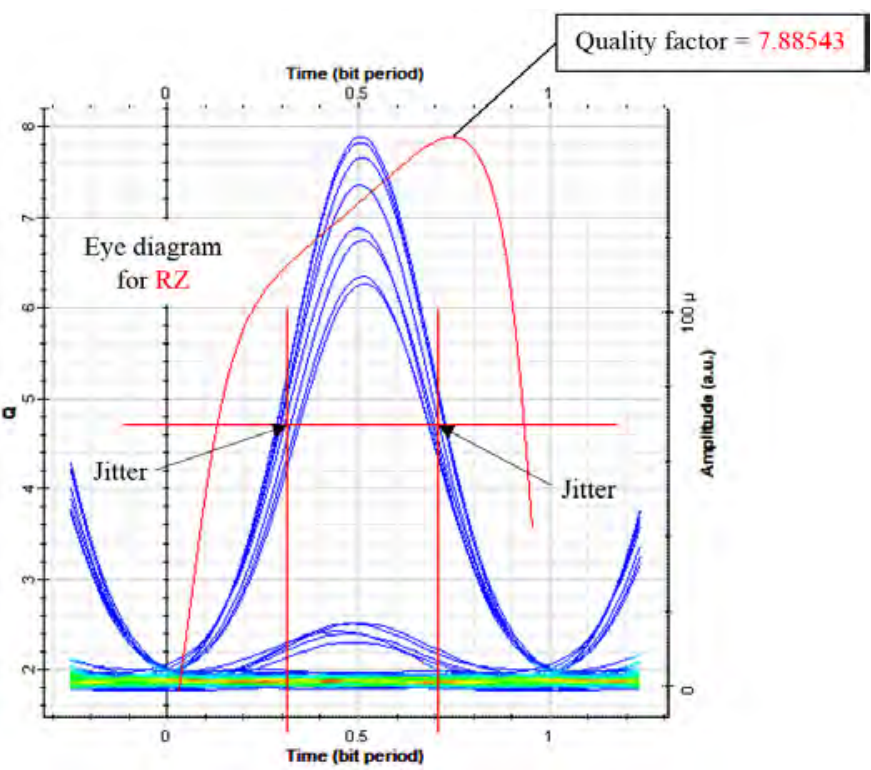

(a)

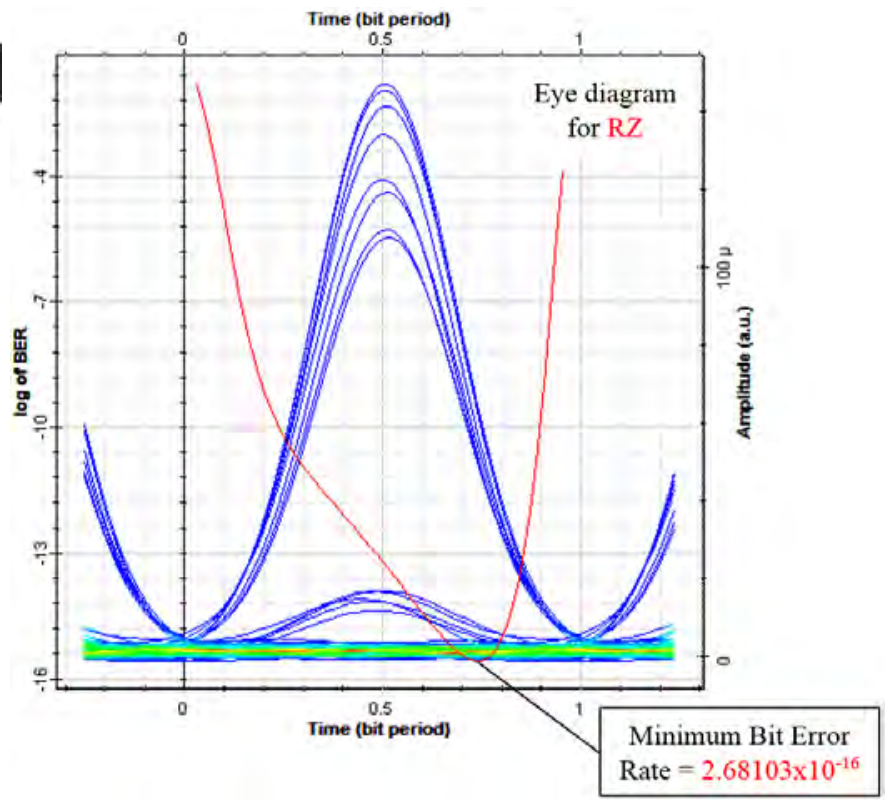

(b)

Fig. 8. a) Q-factor at ch-1 marked by the red curve is 7.88543 , b) Min. BER at ch-1 marked by the red curve is $2.68103 \times 10^{-16}$.

PRBS are used as clock generator, and low pass Gaussian filter connected after Avalanche Photo Diode has a cut-off frequency of $(0.75 \mathrm{x}$ Bitrate). All criteria were kept same as OTDM network. Transmission distance for OTDM-WDM combined network is reported $140 \mathrm{~km}$ [20], $560 \mathrm{~km} \mathrm{[21],}$ $700 \mathrm{~km} \mathrm{[12],} \mathrm{and} 1822 \mathrm{~km} \mathrm{[22]} \mathrm{by} \mathrm{other} \mathrm{authors.} \mathrm{But} \mathrm{the}$ proposed technique in this paper allows $2700 \mathrm{~km}$ transmission at $1550.12 \mathrm{~nm}$ with BER of $2.68103 \times 10^{-16}$ using 384 channels from OTDM. Moreover, the BER values are taken without any FEC, the odds of signal dispersion, shifting of data bits are also accounted for.

In DWDM, channel spacing limits transmission distance because of side modes of each wavelength, cross talk, spectrum interference etc. [23]. Therefore some results are included regarding the change in transmission distance and BER value with respect to channel spacing difference by $0.8 \mathrm{~nm}$ $(100 \mathrm{GHz})$ and $1.6 \mathrm{~nm}(200 \mathrm{GHz})$. All the values of BER are taken from $1550.92 \mathrm{~nm}$ subsystem design at channel 1 for both cases, and are included in Table 2. A graph showing transmission distance and $\log (\mathrm{BER})$ degradation due to change in channel spacing is presented in Fig. 9.
TABLE II. MEASURING BER WITH RESPECT TO TRANSMISSION DISTANCE

\begin{tabular}{|c|c|c|c|c|}
\hline \multirow{2}{*}{$\begin{array}{c}\text { Channel } \\
\text { Spacing } \\
(\mathbf{n m})\end{array}$} & $\mathbf{4}$ Transmission Distance (km) \\
\cline { 2 - 5 } & $\mathbf{0}$ & $\mathbf{2 4 0}$ & $\mathbf{7 2 0}$ & $\mathbf{1 2 0 0}$ \\
\hline 0.8 & -238.89 & -25.454 & -43.303 & -44.489 \\
\hline 1.6 & -970.03 & -3.2938 & -55.584 & -11.581 \\
\hline & \multicolumn{5}{|c|}{$\log (\mathrm{BER})$} \\
\hline
\end{tabular}

TABLE III. MEASURING BER WITH RESPECT TO TRANSMISSION DISTANCE

\begin{tabular}{|c|c|c|c|}
\hline \multirow{2}{*}{$\begin{array}{c}\text { Channel } \\
\text { Spacing } \\
\text { (nm) }\end{array}$} & $\mathbf{1 6 8 0}$ & $\mathbf{2 1 6 0}$ & $\mathbf{2 7 0 0}$ \\
\cline { 2 - 4 } & -15.805 & -19.356 & -14.809 \\
\hline 0.8 & -6.532 & -6.3154 & 0 \\
\hline 1.6 & \multicolumn{3}{|c|}{$\log (\mathrm{BER})$} \\
\hline & \multicolumn{3}{|c|}{} \\
\hline
\end{tabular}




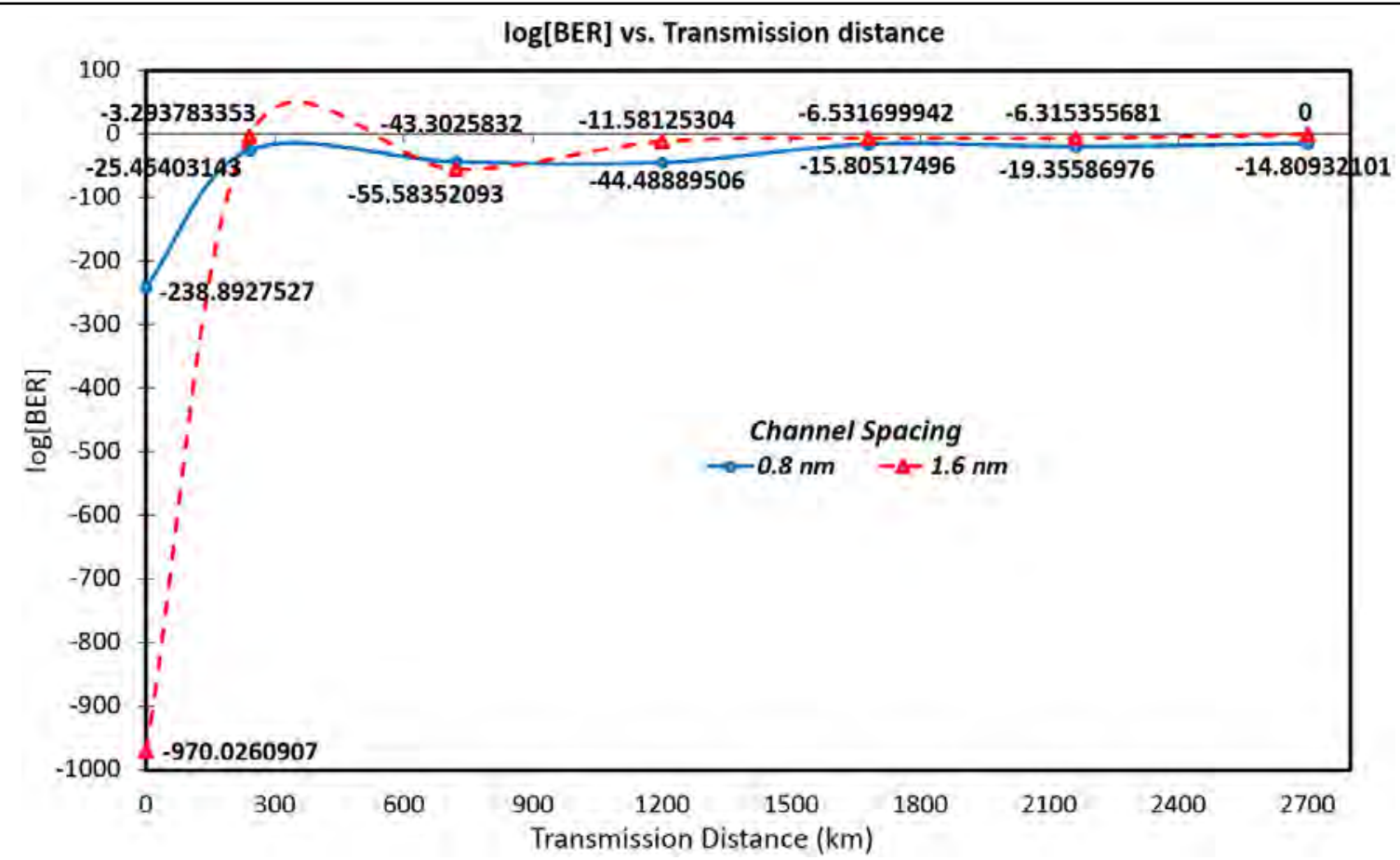

Fig. 9. $\log (\mathrm{BER})$ vs. transmission distance graph from ch-1 shows the significance of channel spacing that effects communication distance. From the graph, the proposed technique for $0.8 \mathrm{~nm}$ spacing (blue curve) has better BER than that of $1.6 \mathrm{~nm}$, so less bandwidth is used in this network.

\section{CONCLUSION}

A complete simultaneous fiber optical communication system has been successfully designed, analyzed, and demonstrated by combining OTDM and DWDM network architecture at $240 \mathrm{Gbit} / \mathrm{s}$ data rate for 2700 kilometers. Moreover, the compression stages provide a room to adapt a maximum number of 384 channels into the network. Throughout the simulation, standard parameters were maintained for commercially available channel grids at $100 \mathrm{GHz}$ [19], carrier capacity at OC-12 [18], only one optical amplifier within each $60 \mathrm{~km}$ span, minimum laser power at $5 \mathrm{dBm}$, maximum user channel under fast TDM technique, and most importantly at less system complexity. The system is efficient, accurate, and still error free while demodulating data in OTDM at a distance of $18000 \mathrm{~km}$ with Q-factor of 6.78312 (BER $<10^{-12}$ ), and demultiplexing in WDM at a distance of $2700 \mathrm{~km}$ with Q-factor of 7.88543 $\left(\mathrm{BER}<10^{-16}\right)$.

\section{ACKNOWLEDGMENT}

A part of this research was supported by IEEE Bangladesh section education activity chair (EAC).

\section{REFERENCES}

[1] K. Tanaka, S. Norimatsu, "Transmission performance of WDM/OFDM hybrid systems over optical fibers," Electronics and Communications in Japan (Part I: Communications), vol. 90, pp. 1424, 2007.
[2] J. Zhang, J. Yu, F. Li, N. Chi, "WDM Transmission of Single-Carrier 400G Based on Orthogonal OTDM 80-GBd PDM-8QAM," IEEE Photonics Journal, vol. 7, pp. 1-6, 2015.

[3] L. Galdino, J. Maranhão, M. Furtado, L. Bonani, F. Durand, E. Moschim, "Evolution of hybrid WDM/OCDM technology in OBS networks with optical code and wavelength conversion," Photonic Network Communications, vol. 25, pp, 47-59, 2012.

[4] Z. Feng, L. Xu, Q. Wu, M. Tang, S. Fu, W. Tong, P. Shum, D. Liu, "Ultra-high capacity WDM-SDM optical access network with selfhomodyne detection downstream and 32QAM-FBMC upstream," Optics Express, vol. 25, pp. 5951-5961, 2017.

[5] B. Guan, C. Qin, R. Scott, N. Fontaine, T. Su, R. Proietti, S. Yoo, "Polarization Diversified Integrated Circuits for Orbital Angular Momentum Multiplexing," IEEE Photonics Technology Letters, vol. 27, pp. 1056-1059, 2015.

[6] R. Poboril, J. Latal, P. Koudelka, J. Vitasek, P. Siska, J. Skapa, V. Vasinek, "A Concept of a Hybrid WDM/TDM Topology Using the Fabry-Perot Laser in the Optiwave Simulation Environment," Advances in Electrical and Electronic Engineering, vol. 9, pp. 167178, 2011.

[7] K. Petrillo, M. Foster, "Full 160-Gb/s OTDM to 16x10-Gb/s WDM conversion with a single nonlinear interaction," Optics Express, vol. 21, pp. 508-518, 2013.

[8] J. Antona, P. Sillard, "Relationship between the achievable distance of WDM transmission systems and criterion of quality for DCM," in 2006 Optical Fiber Communication Conference and the National Fiber Optic Engineers Conference, 2006.

[9] V. Gainov, N. Gurkin, S. Lukinih, I. Shikhaliev, P. Skvortsov, S Makovejs, S. Akopov, S. Ten, O. Nanii, V. Treshchikov, "500 km unrepeatered $200 \mathrm{Gbit} \cdot \mathrm{s}-1$ transmission over a G.652-compliant ultralow loss fiber only," Laser Physics Letters, vol. 12, pp. 066201(1)066201(6), 2015.

[10] B. Zhu, P. Borel, T. Geisler, R. Jensen, L. Leng, X. Jiang, D. Peckham, R. Lingle, D. Vaidya, M. Yan, P. Wisk, D. DiGiovanni, " $800 \mathrm{~Gb} / \mathrm{s}(8 \times 128 \mathrm{~Gb} / \mathrm{s})$ unrepeatered transmission over $515-\mathrm{km}$ large- 
area ultra-low-loss fiber using 2nd-order Raman pumping," Optics Express, vol. 24, pp. 25291-25297, 2016.

[11] D. Chang, P. Perrier, H. Fevrier, S. Makovejs, C. Towery, X. Jia, L. Deng, B. Li, "Ultra-long unrepeatered transmission over $607 \mathrm{~km}$ at $100 \mathrm{G}$ and $632 \mathrm{~km}$ at 10G," Optics Express, vol. 23, pp. 25028-25033, 2015.

[12] M. Nahas, "50 GHz Spaced $4 \times 40$ Gbit/s WDM Transmission over 700 km Using 6 ps Bandlimited RZ Signals," Optics and Photonics Journal, vol. 01, pp. 137-141, 2011

[13] J. Nan, L. Tang-Jun, Z. Kang-Ping, W. Mu-Guang, C. Ming, L. Jing, C. Jian-Feng, “A Clock Enhanced Loop for Simultaneous Error-Free Demultiplexing and Clock Recovery of $160 \mathrm{~Gb} / \mathrm{s}$ OTDM Signal Single-Channel Transmission over 100 km," Chinese Physics Letters, vol. 27, pp. 114213(1)-114213(4), 2010.

[14] Professor Z. GHASSEMLOOY, "All Optical Time Division Multiplexing - An alternative to WDM," Optical Communications Research Group, University of Northumbria, Newcastle, UK. [Online]. Available: http://soe.northumbria.ac.uk/ocr/downloads/otdm/otdmgv1-02.pdf

[15] S. Aleksić, “An ultra-fast photonic ring network employing Optical Packet Compression-Time Division Multiplexing (OPC-TDM) scheme," Electrical Engineering (Archiv fur Elektrotechnik), vol. 83, pp. 223-229, 2001.

[16] W. Hui, W. Jian, L. Jintong, "Packet Compression/decompression for $100 \mathrm{Gbit} / \mathrm{s}$ OTDM Networks," Journal of Optical Communications, vol. 28, pp. 255-259, 2007.

[17] LU Dan, CHEN Ming, GONG Tao-Rong, LV. Bo, LI Tang-Jun, JIAN Shui-Sheng, "160 Gbit/s OTDM Transmission over $100 \mathrm{~km}$ Using Opti-electronics Feedback Loop for Simultaneous Clock Recovery and Demultiplexing," ACTA PHOTONICA SINICA, vol. 39, pp. 1455-1460, 2010.

[18] Optical interfaces for equipments and systems relating to the synchronous digital hierarchy, Itu.int Standard G.957, 2006.

[19] Spectral grids for WDM applications: DWDM frequency grid, Itu.int Standard G.694.1, 2012.

[20] H. Weber, M. Nakazawa, "Ultrahigh speed optical transmission technology," in Introduction to ultra-high-speed optical transmission technology, Springer, New York, 2010.

[21] M. Nahas, "50 GHz Spaced $25 \times 40$ Gbit/s WDM Transmission Over $560 \mathrm{~km}$ Using SMF-Based Large Effective Area Fiber (LEAF)," International Journal of Optoelectronic Engineering, vol. 2, pp. 1720, 2012.

[22] T. Xia, G. Wellbrock, A. Tanaka, M. Huang, E. Ip, D. Qian, Y. Huang, S. Zhang, Y. Zhang, P. Ji, Y. Aono, S. Murakami, T. Tajima, "High Capacity Field Trials of $40.5 \mathrm{~Tb} / \mathrm{s}$ for LH Distance of $1,822 \mathrm{~km}$ and $54.2 \mathrm{~Tb} / \mathrm{s}$ for Regional Distance of $634 \mathrm{~km}$," in Optical Fiber Communication Conference/National Fiber Optic Engineers Conference 2013, 2013

[23] C. Brackett, "Dense wavelength division multiplexing networks: principles and applications," IEEE Journal on Selected Areas in Communications, vol. 8, pp. 948-964, 1990.

[24] T. Islam, M. N. Uddin, "240 Gbit/s Bit Compressed Hybrid OTDMWDM Fiber Optic Communication System," in 2017 IEEE Region 10 Symposium (TENSYMP), Cochin, India, 2017.

[25] T. Islam, M. N. Uddin, "128 Gbit/s 1620 km Hybrid OTDM-WDM Fiber Optic Communication System," AIUB Journal of Science and Engineering, vol. 16, pp. 35-40, 2017.

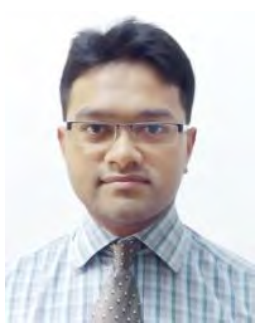

Tadbirul Islam was born in Dhaka, Bangladesh, in 1993. He obtained his Bachelor of Science degree in Electrical and Electronic Engineering from American International University - Bangladesh (AIUB), Dhaka, Bangladesh, in the year 2016. He completed his post graduate degree with a major in networking and communications from the same university in 2018, and received Summa Cum Laude award. His research interest includes analog and digital VLSI circuit design, and fiber optical communication.

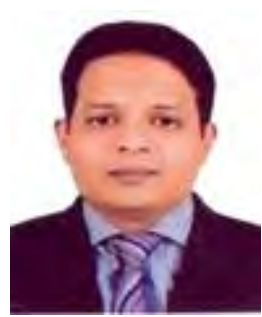

Mohammad Nasir Uddin received B.Sc. degree in Electrical and Electronic Engineering from Khulna University of Engineering and Technology, KUET in 2003 and M.Sc. Engineering in Computer Networks from Middlesex University, United Kingdom (UK) in 2006 and Ph.D degree from Kyushu University, Japan in 2015. He received Professional Engineer Award (PEng.) from IEB Bangladesh (BPERB) during 2017. He started his teaching career as a Lecturer of Computer Science \& Engineering Department of University of Development Alternative (UODA), Dhaka, Bangladesh on February 2004. On September 2006, he joined Department of Computing, The Business School of London, United Kingdom (UK) as a Lecturer. He was appointed as a Lecturer of Electrical and Electronic Engineering Department, Faculty of Engineering, American International UniversityBangladesh (AIUB) on January 2009 and promoted to Assistant Professor during 2010. Currently he is serving as an Associate professor of the same dept. He received monbukagakusho scholarship from Japan Govt. to peruse his $\mathrm{PhD}$ at Kyushu University, Opto-electronics (Hamamoto) Laboratory, Japan. He has received numerous award including Merit Award during M.Sc at Middlesex University, UK, 2013 IEEE Excellent student award from Japan, Deans Plaque for his outstanding research during $\mathrm{Ph} . \mathrm{D}$. His current research interest includes Active MMI Laser Diode, High Speed Optical Communication, Wireless Communication and Optical Sensor network. Dr. Uddin is a member of the Institute of Electrical and Electronics Engineers (IEEE), a member of the Institute of Electronics, Information, and Communication Engineers (IEICE), Japan and LIFE FELLOW of Institute of Engineers, Bangladesh (IEB). During 2016 he served as Vice Chair of IEEE YP and served as an Executive Committee member (Chair of EAC) of IEEE Bangladesh Section during 2017. 